\title{
The Co-operative Study in Action
}

\author{
GEORGE E. CARROTHERS
}

\section{Chairman, General Committee, University of Michigan, Ann Arbor}

WHEN ONE CONSIDERS the number of educational surveys and studies made during the course of the last decade or two and the seeming small amount of attention given the published reports or the insignificant school improvement which has resulted, it is indeed gratifying to note the way the Evaluative Criteria and the Manual of the Co-operative Study of Secondary-School Standards are already being used. So often after reading an inspiring report one says: Well, what can we do about it? Not so with the Evaluative Criteria. They are even now being used extensively throughout the country.

Inquiries from the headquarters office, Washington, D. C., brought prompt, widespread, and enthusiastic responses from rembers of the profession who have had experience with the materials. Some of these will be referred to later; the first thing we desire to present here is the way these materials have been used in one state, Wisconsin. When it was learned that Wisconsin had made such extensive use of the Co-operative Study and that letters from a considerable number of schoolmen had been received concerning experiences with evaluations, request was made and permission was granted to use some of the statements.

On March 19, 1941 Superintendent John Callahan of Wisconsin sent the following letter to approximately sixty schoolmen in his state who had had first-hand experience with the Evaluative Criteria:

"During the current year a considerable amount of the time usually devoted to high-school risitation las been used in evaluating secondary schools through the use of the materials developed by the Co-operative Study of Secondary-School Standards. We have some question in our minds regarding the justification for diverting this time, effort, and expense money from other channels to this particular type of activity.

"To aid us in arriving at a wise descision in this matter, I am soliciting the advice of those schoolmen in Wisconsin who are in the best position to give us guidance. Since you either have had your school evaluated or you have served as a member of an evaluating committee, or both, a frank statement of your opinion of the value of this type of activity as an integral part of our state plan for the supervision of secondary schools will be appreciated.

$$
\begin{aligned}
& \text { Very truly yours, } \\
& \text { (Signed) John Callalian } \\
& \text { State Superintendent." }
\end{aligned}
$$

\section{QUOTATIONS FROM RESPONSES}

Immediate response was received from all of the men. The following quotations are taken from some of the letters: 
1. "I believe that the evaluation of a school through the use of the materials developed by the Oo-operative Study of Secondary-school Standards is an exceedingly valuable exercise for any school faculty to perform. The fact that these 'standards' now take into consideration the needs of the community and the way in which the school is meeting those needs is alone ample justification for the use of materials."-M. U. Batho, Principal, West Bend High School.

2. "The materials developed by the Co-operative Study of SecondarySchool Standards are so comprehensive and yet so flexible that I think they might well be used by all sehools within the state." $\rightarrow J$. Paul Gnagey, Principal, New Glarus High School.

3. "I feel very definitely that the procedure followed by a school faculty preparing for such an evaluation, is an excellent method of providing inservice-training for a high-school faculty. I believe that we will improve our sehool more as a result of the work of the faculty in preparing for the evaluation than by any other project that I know of." $-P$. A. Tipler, Superintendent of Schools, Antigo.

4. "The materials are modern and so thorough they involve the complete educational program, and by checking through the items, factors otherwise overlooked will be brought to the attention of the school authorities."-Laurin P. Gordon, Principal, Johnson Creek High Sohool.

5. "I have taken part in six of these evaluations and consider them among the finest professional experiences I have had in Wisconsin. They offer me the best opportunity $I$ can bave to see high schools at work and to exchange judgments with members of the State Department and with state schoolmen. There isn't the slightest doubt in my mind that your supervisors could not possibly be better employed."-M. H. Willing, Chairman, Department of Education, University of Wisoonsin, Madison.

6. "This type of activity brings about a most searching and detailed inquiry into the philosophy, objectives, and practices employed, to the end that all participating are challenged to justify the things they are doing in our schools in the name of education."- $R$. G. Chamberlin, Principal, King Bigh School.

7. "As far as I am concerned, I feel that the time given to secondaryschool evaluation by your Mr. Merritt is most efficiently used and certainly is highly justifialle. Mr. Merritt does an outstanding job as head of these co-operative studies and is to be congratulated upon the fine and efficient way in which he conducts the same."-H. K. Giroulx, Superintendent of Schools, Marshfield.

8. "My judgment is based on participation in a survey of at least sixty high schools ranging in size from thirty-one students to thirty-four hundred. It is my opinion that the survey of high schools by this method is very, very much worth while."-J. E. Worthington, Principal, Waukesha Junior-Senior Bigh School.

9. "After our evaluation last March, I was so pleased with the manner in which the students and faculty had accepted this visitation that I wrote you a letter recommending extensive use of this method as a supervisory device. After the passing of a year, I am still more enthusiastic. This last January (1941) the schools of the Little Ten Conference and the high schools of Dodge County had a meeting at which time the Evaluative Criteria was 
discussed. Out of this discussion grew a series of monthly meetings which have as their basis of discussion the Evaluative Criteria."-H. C. Ahrnsbrak, Principal, Beaver Dam High School.

10. "We have had our school evaluated and I have also served as a member of an evaluation committee, I can say most frankly that there was never anything done of so large a benefit for this school as an evaluation by a competent committee. To serve on an evaluation committee for even so short a time as two or three days I consider as valuable to the members of the committee as six weeks in a summer school."-George J. Balzer, Principal, Washington High School.

11. "The opportunity for teacher growth, for developing democracy in the administrative and supervisory program, the necessity for evaluating everything that goes on in your school system before the committee visits the school, should be a stimulant for sehool improvement which cannot be obtained in any other manner."-T. H. Boebel, Superintendent of Schools, Medford.

Complete reports from other states are not available, nor is it known that other regions have been able to match this unusually fine Wisconsin record. General reports, however, are available from approximately onehalf of the states. In the following pages some indication is given as to the extensive way in which the Evaluative Criteria and other materials have been used by the regional associations during the first two years since publication.

\section{EXTENT OF THE EVALUATION PROGRAM}

Reports received from approximately one-half of the states during the summer of 1941 show that at least two hundred secondary schools were evaluated during $1939-40$ and another two hundred fifty or more schools during 1940-41. In addition to these four hundred fifty schools reported there were probably another one hundred and fifty to two hundred evaluated and not reported directly to the central office. Total estimates run even as high as eight hundred to one thousand secondary schools studied intensively these past two years by means of materials prepared by the Co-operative Study. The Committee has no way of knowing the exact number which has thus been evaluated.

In addition to these schools, reports have been received that a considerable number of schools were evaluated by committees which were not under the immediate direction of either the university or the state department. Visiting committees were provided and all of the procedures carried out under the initiative and direction of other men who had had contact with the study and who had become so interested that they wanted experience using the materials. To this group should be added at least another three hundred to three hundred fifty schools whose staffs of teachers secured the materials and made use of them for a self-evaluation without the benefit of a visiting committee. These schools felt that a study of the school by the local teachers and administrator would be of considerable value even though securing an outside judgment was impossible. Reports received from the twenty-three states show also that 
in more than four hundred secondary schools these materials were of use to teaching staffs for the purpose of self-study even without the thought of an evaluation. Hundreds of other schools and thousands of teachers used parts of the evaluative materials for the study of special areas of the secondary-school program or the particular departments in which teachers were teaching. For example, the 1940 edition of the M-Blank, a twelvepage pamphlet for securing data on individual staff members, has been sold to numerous schools and to individual teachers to the extent of more than 110,000 copies, many of these in schools not at present contemplating evaluations.

When the reports from all of the schools are combined the clear indication is that at least eighteen hundred to two thousand schools made some use of the Evaluative Criteria and other materials of the study during the years $1939-40$ and $1940-41$. If one were to take the smaller figure and count fifteen teachers to a school, one would find that at least 20,000 to 25,000 teachers became acquainted with the materials during these two years and that a very large proportion of them had a direct part in their use in studying the total program of a secondary school. Probably no other study of secondary education with the exception of the Discussion Group Project of the National Association of Secondary-School Principals ever became so well known or so extensively used in so short a time by so many teachers, laymen, and administrators.

The widespread interest has resulted in part from the decidedly usable materials produced and in part from the direct relationship existing between the regional accrediting associations and their member schools. This open avenue of approach has made it possible not only for the secondary commissions to call attention to the materials but also to furnish trained help for a better understanding and immediate use. The interest, acquaintance with, and use have literally spread out in ever-widening circles. Assuming twenty-five pupils per teacher in schools using the materials one comes to the conclusion that more than a half million pupils are having opportunity to benefit from the improved school conditions resulting from evaluations made during these two years. In addition to these there should be added the two hundred original schools studied and several hundred other secondary schools which used the tentative materials in the 1938 and other editions. Possibly a total of twenty-five hundred schools, forty thousand teachers and one million pupils have had some contact with the Co-operative Study since its first use in 1936-37.

\section{USE OF DIFFERENT SCALES}

It was the feeling of the writer almost from the beginning of the study that as chairman of the Committee he should do everything possible to see that a short measuring rod was provided-something, of course, more extensive than the brief rigid standards formerly used by most of the regional accrediting agencies, yet not as elaborate as the Evaluative Criteria which we were seemingly producing. It is now time for a reversal 
of opinion. The check list of two thousand items included in the first Criteria was later reduced to about thirteen hundred items, but even that number seemed to the chairman of the Committee and to some other members entirely too extensive. As a result, the Committee provided three forms; the long form, or Alpha, the middle form, Beta, and the short form, Gamma, so that schools might have their choice as to length of measuring stick to be used. Now after two years of extensive experience with the Evaluative Criteria it is learned that schools are using only the Alpha, or the long form. In two states some attempt was made to use the shorter forms. However, the results obtained from using the complete instrument are so much more comprehensive and satisfactory that no school is now interested in the abbreviated forms. Some school evaluators indicate, however, that the items should be reduced in number.

\section{PURPOSES OF EVALUATIONS}

One of the inquiries made by the study headquarters during the past summer concerned the purposes back of the evaluation of a secondary school as seen by those who have carried on the evaluations. Some of the expressed purposes are given in the following paragraphs.

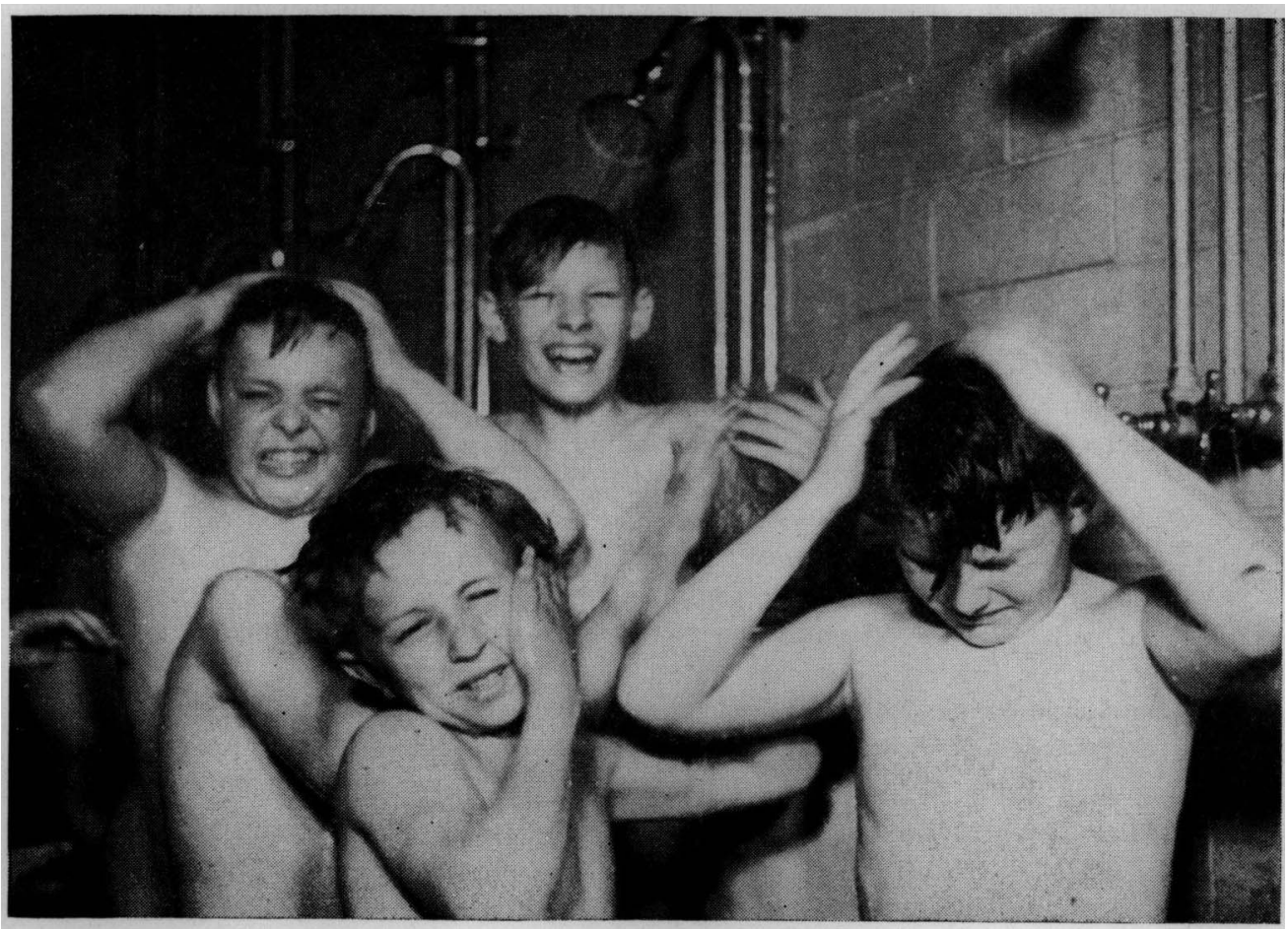

A good shower always follows activities of a strenuous nature in the well-regulated health program of any school. 


\section{Stimulation of Schools}

Reports from the different states mention at least three purposes which seem of considerable significance. Of these, "stimulation of teachers to the doing of better work is given by more than half of the schools as the most important. Those who have carried on the evaluations believe that the in-service training of teachers, the helping of teachers to know what it takes to make a good school and the further knowledge of the way a good school may develop into a better school, comprise the prime purpose of the evaluation. In some instances this is called a self-analysis of the local school situation, and in others it is characterized as stimulation or in-service training of teachers. But whatever the name, this same idea seems to run throughout all reports from schools already evaluated.

\section{Supervisory Objective}

A considerable number of committee members and state chairmen mention that the use of the Criteria in the evaluation of a school results in a definitely improved program of planning and instruction, the very objectives which supervisory activities are always hoping to secure. These materials are bringing to supervisors and directors of instruction a carefully prepared, usable instrument such as they could not have devised in many months or even years. The Criteria cover in considerable detail every phase of the modern secondary school, both public and non-public, large and small, urban and rural. As one Wisconsin man wrote: "There isn't the slightest doubt in my mind that your supervisors could not possibly be better employed."

Accreditation of Schools

A third purpose frequently mentioned is that of accreditation. This, of course, is the one purpose for which the Committee was originally organized. It had been felt for several years that the old standards were too narrow and fixed to serve as a satisfactory measure of a good school or that they could not be used satisfactorily to differentiate between good and poor schools. In at least three of the regional associations a definite feeling had become rather widespread that a better measuring instrument should be developed-hence the organizing of the Committee on the Cooperative Study of Secondary-School Standards. As the work of the Committee continued, it became increasingly clearer that something far better and more useful than merely a measuring rod for accreditation should be produced. It was felt that there was a great need for help and stimulation within the school, and it is now apparent that this is being accomplished. The study, however, did not entirely forget its original purpose. It is evident that already extensive use is being made of the Criteria for accreditation purposes even though it is third in the list of purposes mentioned.

As one means of introducing the use of the Criteria, somewhat more than half of the states require all schools making application for membership in the regional accrediting association, that is, new schools, to have 
an evaluation. In other states the new schools are strongly urged to have evaluations. With schools which are already members, the chief tendency seems to be to evaluate a certain number each year. As more men become familiar with the materials and have experience in the work, larger numbers will be evaluated. It is expected that within the first five to seven years all schools now members of these associations will have been evaluated. Every state chairman, with one exception, reports that more secondary schools are asking for evaluations than can be accommodated. In no region are evaluations limited to member schools or to schools applying for membership.

\section{OUTCOMES AND VALUES}

Apparently one of the greatest values accruing to schools which make use of the Co-operative Study materials is that of the development of a philosophy of education. It was learned during the period of tryout with the original two hundred schools studied that only a small fraction of secondary-school staffs develop and state the philosophy of their particular school. For the most part administrators seem to offer the usual or traditional program without specific inquiry as to the particular purposes and objectives of the school. If the use of the Co-operative Study materials accomplishes nothing else than that of getting teaching staffs to think through, to develop and to write down at least a tentative statement of their philosophy, a great deal will have been accomplished.

Chairmen and secondary-school administrators, almost without exception, have spoken in enthusiastic terms of the value to the school and particularly to the staff of the use of the Evaluative Criteria. Such expressions as the following (summarized) are found in all reports received:

Improvement in service of teachers, supervisors, principals, superintendents, board members, and even custodians were cited. Evaluation resulted in a better organization of the activities program, the guidance procedures, the library, the teaching staff, and the like. A better understanding of local educational problems and better solutions of these were achieved. The most important values arise from the systematic examination of all phases of the school by a group of interested and capable school men. The thorough study of a school by its own faculty makes for a completely different and a most wholesome attitude toward supervisory help from outside the school. A development of community interest and a greater interest in the school on the part of the teachers, together with a consciousness of higher standards is always a benefit to any school. The Evaluative Criteria provide a means for a continuous selfexamination and self-improvement. The participation in these evaluations by schoolmen who have positions of their own is probably the mast valuable thing about the Co-operative Study. Each man is constantly thinking of his own position and possible ways of improving his school. Increased appreciation on the part of teachers of the problems of the supervisor or school administrator is another of the outcomes of an evaluation.

THE PLAN OF VISITATION

Possibly this is the place for one further word concerning the plan set up by the Committee for the evaluation of a school. In contrast to the 
plan devised by the Commission on Institutions of Higher Education of the North Central Association, whereby a small number of paid investigators examine a college, it was decided that the examinations and evaluations should be done by local teaching staffs and outside groups of experienced men who are themselves working in and concerned with secondary education. The evaluation of a school starts months ahead of the arrival of the outside committee. The various materials are purchased by the school, staff meetings are held to consider problems of a general nature, committees of local teachers are appointed to study and be responsible for different areas, studies are carried on during the following months by the local faculty, meetings of committees and of the entire staff are held from time to time to consider findings and possible improvements, then as a culmination of the local school study, and prior to the arrival of the outside evaluating committee, a summary report is prepared. The teachers themselves have studied intensively their own school while actively engaged in teaching, making use of the detailed lists of suggestions in the several areas of the Criteria. In the words of many teachers, it is difficult to think of a better means of self-education than that devised by and provided for in the Evaluative Criteria of the Co-operative Study of Secondary-School Standards.

When the outside committee arrives the teachers are not only intimately acquainted with the measuring instrument to be used on the school, they are also aware of most of the strengths and weaknesses of their own school. They are much better prepared to discuss intelligently with the committee the possible ways of improving the school and they are more sympathetic toward the study than is the case when a paid examining committee does all the work. As a means of in-service training of teachers the Co-operative Study has produced an excellent instrument whether a school desires to become a member of an accrediting association or not. This is one of the most important contributions the regional associations have made to secondary education. It is not as easy to measure the teacher growth and actual improvement as it is to measure the school plant, the number of books in the library, the semester hours earned in college by teachers, and other objective data, yet it is a satisfaction to an administrator just to feel the growth taking place.

\section{IMPROVING ON RECOMMENDED PROCEDURES}

While in a considerable number of the reports received, definite statement is made that no way has as yet been discovered for improvement on the procedures outlined in the Manual, there are a few suggestions worthy of attention. One of the first and most frequent suggestions is that of having college courses in the use of the Criteria. This has been done in a considerable number of colleges and universities, especially in summer schools. Members of the classes taking the course frequently participate in an evaluation in addition to a study of the materials. In at least one instance the members of a class became the evaluative committee 
and prepared the summary report as the term report in the course. Another suggestion, coming from the chairman of one state committee, is that he believes it will have a salutary effect to have in the preliminary meeting the superintendent of schools, members of the board of education and representative citizens for the discussion of the philosophy and objectives of secondary education and for the consideration of the local school and community problems.

\section{THE OUTSIDE COMMITTEE}

\section{Selection of the Committee}

It is quite apparent that no one way has appealed to secondary schools for the selection of the evaluating committee. The plan most frequently employed, in fact used in at least half of the schools, is that of co-operation between the state chairman and the head of the school to be evaluated. The school sends to the state chairman a list of names of educators who might be included, with the suggestion that the state chairman add others as he thinks best and then from that list select the committee. In some instances the order is reversed, the state chairman sends a list to the school together with the suggestion that the principal be responsible for naming the members of the committee to be invited by the state chairman. In each instance the school either suggests names or reserves the right of veto on any names suggested.

The chairman in either case is usually assisted by members of the state department of education and by members of the department of secondary education of the state university. In few instances does it seem that the state chairman alone is responsible for the selection of the committee.

In a considerable number of schools the head of the school has been asked or permitted to choose the outside committee. A list of prospective members is usually made up locally and sent to the state chairman for the veto of any names of men whom he might consider not entirely satisfactory for that particular evaluation, and for the including of the names of other men who might be qualified and available. The total list is then returned to the head of the school being evaluated and he in turn appoints the committee and invites the different men to come to his school on the dates set. It is not known at the moment whether this works out satisfactorily. There is grave doubt in the mind of the writer however, that a committee selected in this manner would feel entirely free in rendering a completely factual report, especially if rather unsatisfactory conditions were discovered in the school. Some state chairmen feel strongly that it would be a mistake to have the outside committee selected by the administrator of the school to be evaluated.

\section{Composition of the Committee}

The composition of committees seems to vary but little within a given state or area or throughour the United States. The evaluating committee is usually in charge of the state chairman or his assistant or some- 
one else chosen for the particular task in hand. The other members are secondary-school principals, usually two or three; city superintendents, one or two; a college professor, or the dean of the school of education in the vicinity; representatives of the state university and state department of education, one of whom is usually chairman of the committee; several teachers; and an occasional junior high-school principal or county commissioner. One man says he has not been very successful as yet in using college professors, while in other instances these men have been very satisfactory participants in evaluations.

It is quite apparent that state chairmen have been taking the lead in arranging for evaluations and the selection of committees, yet no one pattern of representatives has been followed. Apparently there is a definite attempt in every instance to secure a well-balanced committee. The idea seems to be, and this is as suggested by the Co-operative Study Committee, that well-trained, active men and women in the field of secondary education, whether in schools, colleges, state departments, universities, or other places, should be selected for work on these evaluating committees. The working out of this suggestion is indeed gratifying. It means that an everincreasing number of educators are becoming acquainted with the study and are having enjoyable, profitable, and practical experience in carrying through the evaluations.

\section{Number on the Committee}

The committee usually consists of from eight to ten persons. In some instances schools have been evaluated by a committee of only two persons and in other instances the number has reached twenty-five to thirty. No one seems to feel, however, that a committee of fewer than six to eight can do a thoroughly satisfactory job, and the larger the school the more members needed for the evaluation. Some chairmen desire twelve to fifteen or even up to twenty members, but no one has found that more than twenty can be organized to work together effectively. The ideal number seems to be from ten to fifteen.

\section{Days and Work}

In at least one instance a committee was selected and so organized that a school was evaluated in one day-a day which seems to have been as greatly extended as the last day of the usual state legislature. This committee went to work early in the evening of the previous day and continued until after midnight. The day of the evaluation the different members worked from early morning until late afternoon, then spent most of the second night writing up the report. It is not known just how satisfactory the committee felt it had done its work, but it did do the job in the one day-that is, the schoolmen were absent from their own places of business only the one school day. The chairman had the "feeling that many of these committee members are not good for much for a day or two after returning to their jobs, but they seem to feel better about it if they are not away from home too long." The same comment has been received 
from many chairmen even in instances where several days were taken tor the evaluation. The evaluating of a secondary school is a strenuous task.

The most frequent number of days reported for the evaluation of a school is three to five depending somewhat on the size of the school, the number on the committee, and the experience of the members in previous evaluations. Three days seem to be necessary for even a small school, and in only a few instances has it been considered necessary to take more than five days. A considerable portion of the examining can be accomplished in two days. In practically every instance a lengthy preliminary meeting is held on the evening previous to the beginning of the school evaluation. During the following two days a considerable portion of the detailed school study is made and on the third day reports are written up. When additional checking on items in the school needs to be made this can be taken care of while the reports are being prepared. The fourth day can then be used for the report to the school authorities. If time permits and if the school is quite large, a fifth day may be necessary. Or, if time is short, the report can be made the evening of the third day. Three long days and four extended evenings will serve in many instances as suffcient time to make the study and render the reports. Then, when this "vacation" trip is over, as with other vacation trips, the participants return to their homes to rest up and get ready to go back to their own work. But in no instance coming to the attention of the writer, has any member said he regretted the experience of participating in the school evaluation.

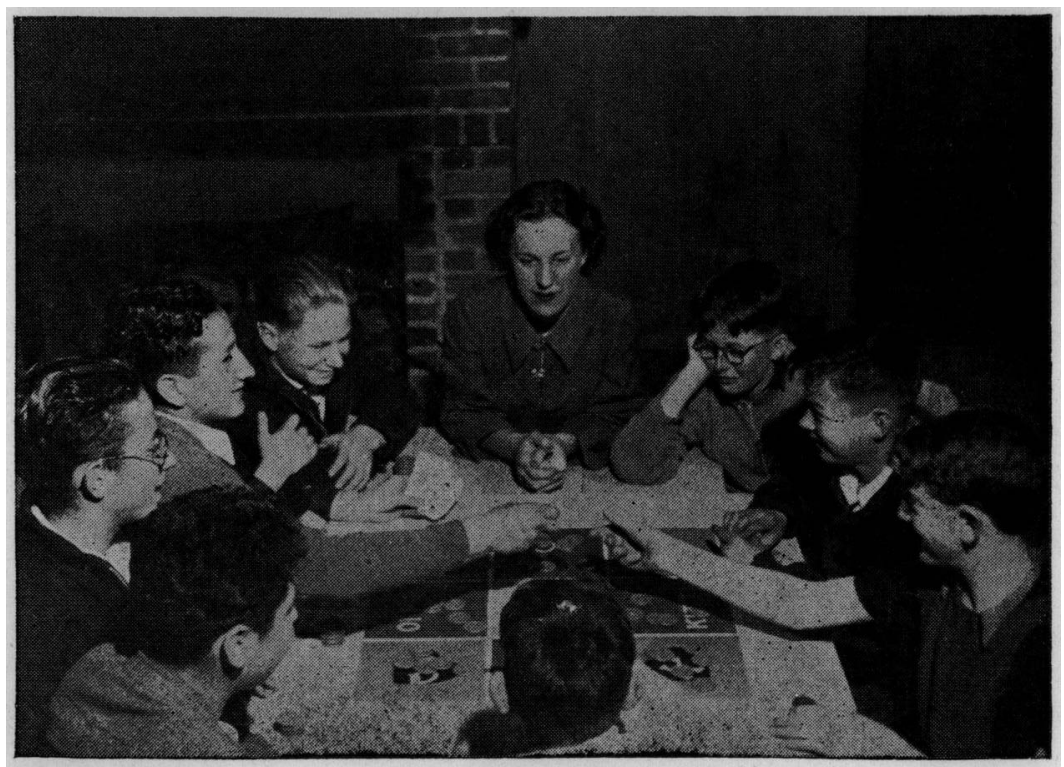

The health and physical education program of this school provides for a wide variety of pupils' interest and physical makeups. Here pupils participate in games of a less strenuous type. 


\section{Training of Committees}

Preliminary meetings are nearly always held for the purpose of training new members of committees. This is necessary since every school is a new situation with new problems and since in most instances from onefourth to three-fourths of the committee are new and inexperienced in that particular kind of school examination. The chairman, assistant chairman, the heads of the different examining divisions, and possibly others will be teachers or administrators experienced in evaluations. Many, and in some instances all, of the rest of the committee will be new.

Some schools of education have given courses in The Evaluation of Secondary Schools, using the Co-operative Study materials as the basis of instruction and have in this way greatly helped in the training of men and women for participation in school evaluation. Individual classes have even undertaken the evaluation of a particular school and have thus prepared several teachers, not only for individual committee work but also for the important position of chairman. Participation in the writing of reports is found to be a very effective way to train teachers, and anyone who loses out on this activity misses much of the value of the total experience. In some states, meetings have been regularly scheduled at the time of the state or regional teachers meeting for the acquainting of secondary-school teachers with the Evaluative Criteria and for the training of prospective leaders. In other instances rather elaborate mimeographed bulletins on the use of the Criteria and the Manual have been developed and distributed to committee members prior to the preliminary meeting. In at least one state a bound volume has been published explaining the plan for using the Evaluative Criteria. ${ }^{2}$ It is clear that there has been a definite, widespread and conscientious effort to have everything and everybody ready for the special three to five days of work so that as complete and satisfactory an evaluation as possible may be accomplished.

\section{The Committee Report}

That the making of both oral and written reports has been taken seriously is shown by the care in preparation and the length of the reports rendered. There is always an oral report made to the school authorities and a written report handed in for future study. The length of the report, of course, is partially dependent on the size of the school and the members of the committee, but it is also dependent on the findings of the committee in their use of the check list items in the several areas and the evaluations agreed on. While some reports have been rather brief, and one at least has been unusually long (100 pages), the usual report contains from six to twenty pages of typed material. In almost all of the evaluations, the committee presents part of the report in graphic form, using the Educational Temperatures outlined in the Manual. Just why

\footnotetext{
${ }^{1}$ Eikenberry, D. H. and Byers, C. C. The Oino Plun of Using the Evaluative Criteria of the Co. operative Study of Secondary-School Standards, Columbus, Ohio. F. J. Her Printing Company, 286 South Fourth Street. 1941, 255 pp. paper \$.75, cloth $\$ 1$.00.
} 
it has happened is not known but reports indicate that the western and northwestern states have preferred to leave to the local school the computing of the different exact scores and the prparation of charts. They seem tc feel that schools will study their own reports with greater care if the computations are not made. When the computations are omitted and the charts are not prepared, the school does not spend time trying to compare local scores with reports from other schools. In a large majority of cases, however, the charts have been prepared and included.

The oral report is made to the administrator of the school and to selected members of the staff. Heads of departments and supervisors of special areas are usually included in this meeting. In many instances nembers of boards of education are invited and at times other leading citizens. In some evaluations the entire teaching staff is included in the final meeting. The desire seems definitely to be that of making the findings as widely known as possible with the idea that these reports together with the questions and discussion which follow are an integral part of the education of the staff and the laying of foundation for an improved school. All of which is decidedly encouraging.

\section{Expense}

The expense of evaluations is a problem yet to be solved in many localities. Some boards of education or trustees of schools take care of all local expenses while in other instances no expense money is provided. In a very large majority of instances members of the committees not only give generously of their time and talents but they also provide the transportation and other expenses. In a fair proportion of evaluations the regional association has taken care of the expense of the chairman if he has worked outside his own state, and more recently his expenses have been paid even within his own state. In some instances the chairman can charge his expenses to his local budget provided for by the state department of education or the university of which he is a part. In several cases special research or lecture funds have been tapped for a small amount, but on the whole the active participants in school evaluations have been the ones who have had to stand the expense. In addition, these men have frequently had to do considerable extra work on returning home since seldom is it possible to obtain substitutes to take their places while they are away.

\section{SPECIAL PROBLEMS AND IMPROVEMENTS}

\section{Securing Committees}

From the inception of the plan to have schools evaluated by active members of the profession it was anticipated that there would be difficulty experienced in obtaining a sufficient number of committee members to do an efficient job in every school. Thus far, however, this anticipated difficulty has seldom been met. This is partly due to the fact that only a small proportion of the total number of schools is being evaluated each year, and also to a larger degree to the widespread interest which has de- 
veloped in the Criteria and to the desire of schoolmen to become better acquainted with their use. The response has indeed been gratifying to the General Committee and to the sponsoring regional association.

In some states there has begun to appear a slowing down of responses to invitations to participate in evaluations as larger and larger numbers of men have had active experience in one or more studies, and as schools receiving the benefit of the evaluation have seemed reluctant to meet the expense. So far practically all schools desiring evaluation have been provided for. In time, however, it is foreseen that some changes in procedure for securing committee members and for paying expenses will need to be worked out. This will be specially true if regional associations decide that all member schools shall be evaluated sometime during the first five to seven years from the publication of the Criteria.

\section{Computations}

One of the very difficult problems for some committees is that of the computations and the preparation of the Educational Temperature charts. Some graduate schools and research bureaus have graduate students who can be trained to handle these since the computations are not very difficult once the procedure is fully understood. In other states there seems to be no person to handle this phase of the evaluation and no institution available to take over the job. This presents a real problem in some areas, yet it does not seem to be a widespread problem. Presumably in a reasonable length of time a sufficient number of trained men and women will be available to make all computations required.

\section{Symbols}

One of the problems mentioned by a considerable number of schoolmen is that of the use of the +,-, and 0 characters. Also the use of " $N$ " to which a number of men have taken exception. The use of these symbols was discussed at length in committee meetings before a decision was reached to use them. They seemed to be the best and most convenient available at the time, hence the authorization of their use. As yet no one has suggested better ones even though the limitations in the use of these has been recognized, but suggestions for improvements will be appreciated.

\section{USE OF THE CRITERIA}

In reporting on those parts of the Evaluative Criteria which seem the least satisfactory the following statements were quite typical: "We have made no critical examination with a view to their improvement." "We have accepted them and used them and have been surprised and pleased with the effectiveness with which they can be applied to different school situations. In some instances, however, certain parts have been pointed out which are not as satisfactory in their use as the Criteria as a whole. The section on the Philosophy and Objectives and the one on Outcomes of the Educational Program seem to present difficulties." "Some of the items in philosophy insist that one be a so-called progressive to get 


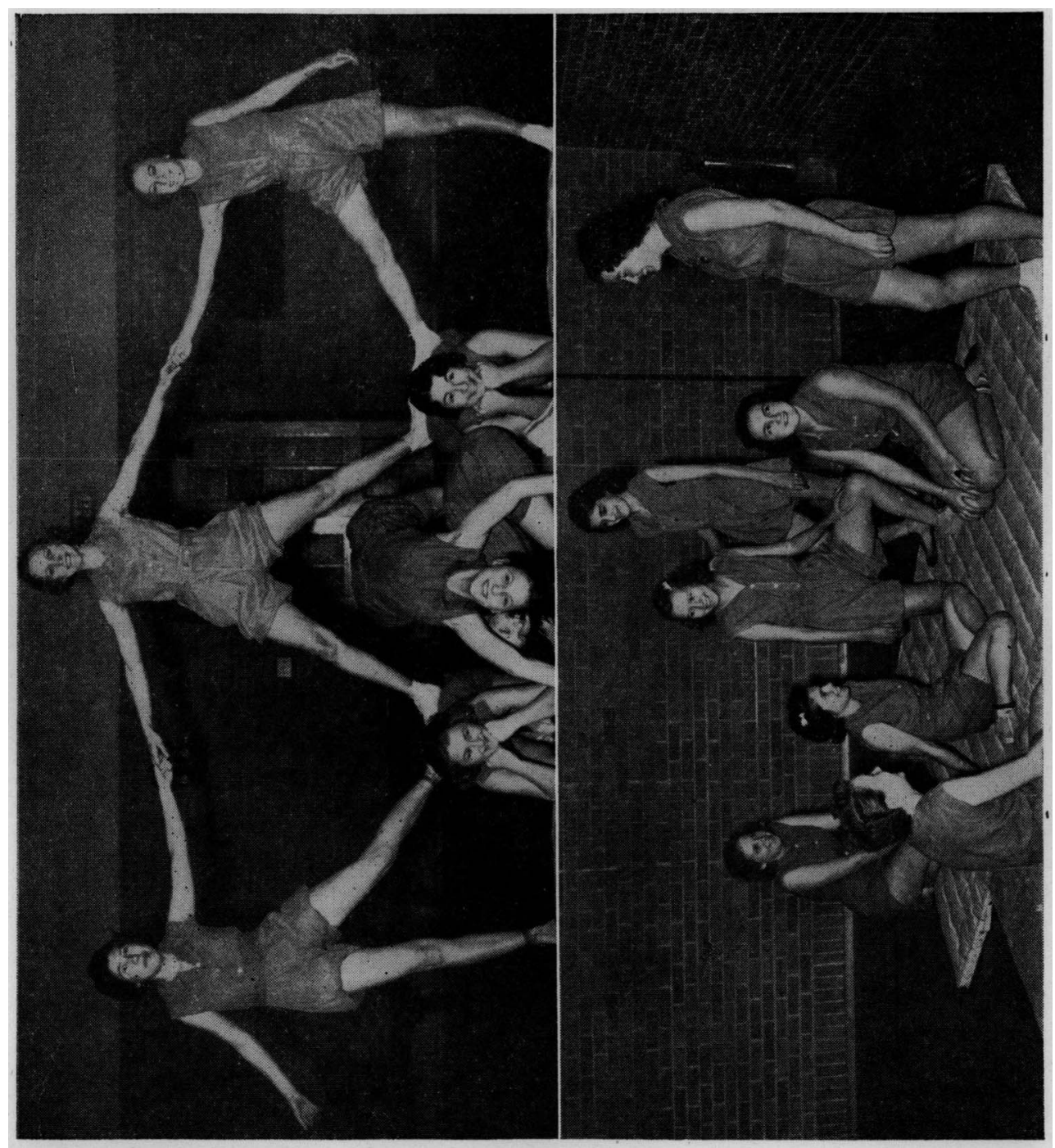


the better rating, whereas I am very doubtful that some of the preferred ratings are good judgment." One state chairman says committee members balk at evaluating Outcomes. Members of some committees have discussed the possibility of starting a testing program, yet this seems to be quite infeasible. Certain parts of the $\mathrm{M}$ blanks are not considered entirely satisfactory, particularly the value accorded the work taken in the secondary school. A considerable number hope that the items to be checked may be reduced in number. On the whole, however, the check list items and evaluations appear to be surprisingly satisfactory. The difficulties referred to were not mentioned in a number of instances.

In reporting on those parts which seem to be most satisfactory every section is mentioned by some of the secondary-school men participating in evaluations, and most of these sections are mentioned many times. Several comments were to the effect that the materials are so well prepared and so effective in their use that they should be used for the time being without any changes. One man said he couldn't think at present of any way to improve on the Criteria but that he would try during the next year to discover something so he could make suggestions. In discussing the phases of the evaluation process which are least satisfactory attention was called to the computation of teacher preparation and improvement in service, other activities under teacher load and a few other individual phases of different sections. Again, on the whole, it appears that the process suggested is working out quite satisfactorily.

It is of interest to those who have spent several years developing the Manual and The Evaluative Criteria to note the numerous ways beyond the secondary-school area in which adaptations have been devised for special uses. One of the first and most extensive adaptations and uses was that employed by the committee on the study of Junior Colleges under the direction of Dr. Walter C. Eells who, as the Co-ordinator of the Cooperative Study of Secondary-School Standards, had rendered such effective service during most of the time the Criteria were being developed. Other adaptations have reached down into the junior high-school field and in some states and local areas even further down. One state superintendent says he is sure the committee will be interested in knowing that second. ary-school men in his state have been so enthusiastic about the values received from the use of the Evaluative Criteria that a very concerted movement is under way to have such Criteria developed for use in the elementary schools. A letter and bulletin sent recently to state chairmen from the Federal Security Agency, United States Office of Education, Vocational Division, Washington, D. C., on Evaluative Criteria for Vocational Education in Agriculture show quite clearly the extent to which still another area has found the Criteria useful. Considered broadly the results already secured seem fully to justify the expenditure of funds and the five or six years of work on the part of the committee on the $\mathrm{Ca}$ perative Study of Secondary-School Standards of the regional associations. 